A pesar de la opinión general, la autotraducción es una práctica tan extendida como interesante, desde múltiples puntos de vista. Este artículo tiene por objeto realizar una breve introducción tanto de su historia como de las múltiples variantes del fenómeno en general, así como de su importancia en los estudios literarios y de traducción.

PALABRAS CLAVE: autotraducción, traducción, literatura comparada, traducción literaria, historia de la traducción.

\title{
Más allá de la traducción: la autotraducción
}

María Recuenco Peñalver

Universidad de Ciudad del Cabo

\section{Beyond Translation: Self-Translation}

Despite the general opinion, the practice of selftranslation is, from multiple points of view, as wide as interesting. This article aims to make a presentation of its history and the multiple variants of the phenomenon in general, as well as its importance for literary and translation studies.

KEY WORDS: self-translation, translation, comparative literature, literary translation, history of translation. 


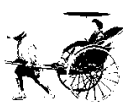

What is the point of using two languages, If you are going to write the same kind of poem in each? Cristopher Whyte, Against Self-Translation

194

\section{INTRODUCCIÓN}

Durante la celebración de las XIV Jornadas en torno a la traducción literaria en Tarazona, Eduardo Mendonza dijo que no hay muchos autotraductores («creo que podríamos contarlos con los dedos de una mano»), que la autotraducción es algo muy excepcional y que «se da en el caso de los catalanes y poco más, quizás algún gallego», porque el catalán es «una de las pocas lenguas en que, por sus circunstancias, sus peculiaridades, la autotraducción se ha practicado casi de una manera masiva».

Menos mal que el propio Mendoza se ha autotraducido. Esto es, ha traducido al menos una de sus obras a un idioma distinto del que usó en un primer momento. En concreto, una obra de teatro, Restauració, del catalán al castellano. Según él, su experiencia con la autotraducción le ha demostrado que se trata de algo sumamente difícil y antipático: «uno sabe lo que quiere decir y por qué lo dijo de esa manera y la sensación de estar cambiando algo se hace muy presente; cosa que no ocurre cuando lo ha escrito otro».

Lo que más llama la atención de la opinión de Mendoza (y de otra mucha gente) es el imperante desconocimiento (que incluso, en ocasiones, llega a desprecio) de la realidad de la autotraducción. Porque haber autotraductores, haylos, siempre los habido y siempre los habrá, además de que la autotraducción goza de una larga tradición en el mundo literario en, prácticamente, todos los géneros.

\section{LA AUTOTRADUCCIÓN TAMBIÉN TIENE SU HISTORIA}

Julio César Santoyo (2002a) afirma que «la autotraducción no es [...] "característica de la particular configuración lingüística y cultural de la Europa del Renacimiento" (como se ha dicho), sino característica, en pleno siglo $\mathrm{XX}$ o XXI de Canadá y de los Estados Unidos, de la India, España, Rusia o Sudáfrica, como característica lo ha sido igualmente en cualquier otro tiempo, desde la Edad Media a estos mismos primeros meses del año 2002...».

$\mathrm{Y}$ es que el primer autotraductor del que se tiene conocimiento es el historiador judío Flavio Josefo, quien escribió en arameo, su lengua materna, los siete libros de su primera obra $L a$ guerra de los judios para, años después, en torno al 75 de nuestra era, revisarla y traducirla al griego. Posteriormente, en plena Edad Media, otro sabio judío, Abraham Bar Hiyya (ca. Io65-ca. II45), matemático y astrónomo residente muchos años en Barcelona, parece haber compendiado en árabe y luego traducido al hebreo, a petición de los judíos del sur de Francia, sus Fundamentos de la inteligencia y torre de la fe. Su ejemplo fue imitado años después por el judío toledano Yehuda Ben Salomón Cohen, autor en árabe y hebreo del tratado enciclopédico titulado en latín Inquisitio sapientia. En Inglaterra, se atribuyen a Robert Grosseteste (ca. II68-I253), obispo de Lincoln, iniciador de la tradición científica de la Universidad de Oxford y uno de sus primeros cancilleres, unos Estatutos o Reglas para el gobierno de la familia y de la hacienda en latín, francés e inglés. Con seguridad, Mendoza también olvida a Ramon Llull (I232-I3I6), autor de una ingente obra en catalán, latín y árabe y uno de los autotraductores más prolíficos de la Edad Media europea. En árabe escribió sus primeras obras, La lògica del Gatzell y el extenso tratado Llibre de contemplació en Déu, que luego tradujo al catalán y al latín. En la otra dirección, su Libre del gentil $e$ dels tres savis parecer ser una autotraducción del catalán al árabe. En el año I300, Llull completaba en catalán su Liber de esse Dei, en cuyo prólogo 
manifiesta su intención de traducirlo al árabe. Al final de sus días, durante su estancia en Túnez, y quizá debido a su mala vista, Llull contó con la ayuda de Fray Simón de Puigcerdá para la realización de una versión latina de hasta quince de sus obras escritas en catalán. A esta época pertenece, por ejemplo, Liber de consilio divinarum dignitatum, fechado en Túnez en mayo de I315, en cuyo colofón latino se afirma que fue inicialmente escrito en árabe, traducido por Llull al romance y de ahí de nuevo al latín.

En la península ibérica, la autotraducción experimentó un espectacular florecimiento en el siglo XV. Enrique de Villena escribió «en romançe catalán» Los dotze treballs de Hèrcules y «después trasladolo él mesmo en lengua castellana a suplicaçión de Iohan Ferrández de Valera el moço su escribano...». Pocos años después, Alonso de Madrigal, el Tostado, profesor en Salamanca y obispo de Ávila, componía en latín a petición de Juan II y traducía posteriormente al vulgar un Brevyloquyo de amor e amiçiçia. Ejemplo que siguió Alonso de Cartagena, obispo de Burgos, con cuatro obras propias, entre ellas una Contemplación... sobre el pesalmo del profeta Davit que comiença júsgame Dios, de las que sólo se conserva actualmente la versión castellana. Algo posteriores pero todavía del siglo $\mathrm{XV}$ son dos versiones propias en latín y en castellano de Alfonso de Palencia, Batalla campal de los perros contra los lobos (I457), una alegoría política de la que también se ha perdido el original latino, y Tratado de la perfección del triunfo militar (I459), versión del autor de su anterior De perfectione militaris triumphi; además del prólogo y el epílogo bilingües a su Universal vocabulario. Antonio de Nebrija también transladó «contraponiendo renglón por renglón el romance al latín» el texto de sus Introductiones Latinae por encargo de Isabel la Católica, al igual que hizo también con los prólogos bilingües al Lexicon ex sermone Latino in Hispaniensem y al Dictionarium ex Hispaniensi in Latinum sermonem. Del condestable don Pedro de Portugal se conserva una Sátira de infelice e felice vida, escrita primero en portugués y después traducida por el autor al castellano durante los años de su exilio en Castilla.

En cuanto a los siglos XVI y XVII, época en que era común en Europa que los poetas tradujeran sus meditaciones escritas en latín como un simple ejercicio manual, coinciden Santoyo (2002a) y Rainier Grutman (1998) en afirmar que se caracterizaron por una eclosión de la práctica autotraductora. En Francia numerosos fueron los escritores que realizaron autotraducciones del latín o incluso del griego al francés y viceversa. Entre ellos cabe destacar a Bernand Du Poey y Amadis Jamyn, François Moeam, Jean Dorat, Remy Belleau, Louis De Masures, al conocido teórico de la traducción Étienne Dolet, al poeta Joachim du Bellay, miembro de la escuela francesa de la Pléyade, o al reformador protestante Juan Calvino, traductor al francés de sucesivas ediciones de sus Christianae religiones Institutiones. En Italia, el cardenal Pietro Bembo compuso primero en latín y luego en vulgar los doce libros de Historia de Venecia. En Portugal, Pedro Nunes hacía lo propio del portugués al castellano con su Libro de álgebra. En Inglaterra, Tomás Moro tradujo al inglés su obra en latín Historia de Ricardo III y John Donne escribía en latín una sátira feroz, Conclave Ignatii, para traducirla posteriormente al inglés. Algo más tarde, lo mismo hicieron con composiciones propias los poetas Abraham Cowley y Andrew Marvell. En los Países Bajos cabe recordar las versiones propias de Hadrian Damman, Constantijn Kuygens, Jacob Cats y Jan Van Der Noot, cuya obra Olympia apareció en 1579 en una edición bilingüe, en francés y en alemán, sin olvidar la figura del filósofo Baruch Spinoza, traductor del latín al 
holandés de su Breve tratado sobre Dios, el Hombre y su Bienestar (166I), del que sólo se conserva el texto traducido. Se debió, con seguridad, al hecho de que, como afirma Leonard Forster (I970), a finales de la Edad Media y durante el Renacimiento, los poetas europeos eran frecuentemente bilingües y escribían sus obras en varios idiomas, destinadas a un público también políglota.

En España hay que mencionar a Fray Luis de León, quien después de componer su primera obra en prosa para la monja Isabel Osorio, la Exposición del Cantar de los Cantares, recibió orden de sus superiores de traducirla al latín, o a Pedro Simón Abril. Otro ejemplo es el jesuita Pedro de Ribadeneira, autor de Vita Ignatii Loyolae (1572) que traduce del latín al castellano, o el de otro jesuita, Juan de Mariana, quien después de escribir en latín su Historia de España realizó la autotraducción al castellano. Un siglo más tarde, en México, Sor Juana Inés de la Cruz (1651-1695) escribe en latín un epigrama en dísticos elegíacos a la Inmaculada Concepción para después traducirlos a coplas castellanas.

El elenco (siempre incompleto) de autotraductores, ocasionales o sistemáticos, durante los siglos XVIII y XIX incluye, entre otros, a los italianos Giuseppe Baretti, Carlo Goldoni o Salvatore Di Giacomo, a los ingleses Robert Lloyd y al médico John Brown, al dramaturgo Francisco Martínez de la Rosa, a Joseph Perl y a Mendele M. Sforim, escritores ambos en hebreo y yiddish, a los franceses Stéphane Mallarmé y Frédéric Mistral y al antillano Alexis SaintLéger (Saint-John Perse), a Samuel Bond y a Miguel Antonio Caro en Colombia, a Stefan George en Alemania, a Honoré Beaugrand y a Louis-Honoré Fréchette en Canadá...

Con posterioridad, los autores que se han traducido a sí mismos forman un grupo tan amplio y tan diverso que resulta imposible enumerarlos a todos. En cualquier caso, cito, a modo de muestra, los nombres del polaco Czeslaw Milosz; Talât Sait Halman en Turquía; Vladimir Nabokov en Estados Unidos; Gabriele D'Annunzio en Italia; Hector Bianciotti en Argentina; Ariel Dorfman en Chile; el peruano José María Arguedas; el cubano Gustavo Pérez Firmat; en Francia, Roman Gary; el brasileño Joâo Ribeiro; Isak Dinesen (Karen Blixen) en Dinamarca; André Brink en Sudáfrica; Ngugî wa Thiong'o en Kenia; Rosario Ferré en Puerto Rico; la mexicana Gloria Anzaldúa; Rabindramath Tagore en la India; la rusa Marina Tsvetaeva; el moldavo Ion Drutse; el tayiko Timur Pulatov; Olzhas Suleimenov en Kazajistán; o el bielorruso Vasil Bykovi, etcétera.

En los países o sociedades plurilingües el paso, mediante la autotraducción, de una lengua denominada «regional» a la lengua oficial del Estado o lengua dominante en el mercado resulta tan lógico como complicado. Un claro ejemplo de ello es Bélgica, territorio tradicionalmente fértil para el contacto lingüístico entre el flamenco y el francés, y que cuenta con un importante número de autores bilingües. Grutman (1998) pone fecha al ejercicio de la autotraducción y defiende que la aparición de las primeras autotraducciones data del período comprendido entre 1924 y 1960, con un gran incremento entre I935 y 1960. Destaca a cinco escritores flamencos pertenecientes a dos generaciones: los miembros del primer grupo formado por Jean Ray, para el público francés; John Flanders, para el flamenco; y Roger Avermaete y Camille Melloy, que optan por publicar sus textos bien en francés, o bien en flamenco tras haber escrito una primera versión en francés, la lengua adquirida; y los del segundo grupo, más jóvenes, Marnix Gijsen y Johan Daisne, quienes comienzan escribiendo en

I Para más información véase el artículo de Dadazhanova (I984). 
flamenco para, unos años más tarde, realizar la versión en francés. En España, el ejercicio de la autotraducción es muy frecuente, y se viene realizando prácticamente desde siempre, en tierras vascas, gallegas y catalanas, donde la proliferación de autotraducciones tuvo lugar en el siglo XX, según Cristopher Whyte (2002), sobre todo, tras la muerte de Franco. Ya en i9r6, en Londres, Ramiro de Maetzu publicó en inglés su ensayo Authority, Liberty and Function in the Light of the War, que autotradujo y editó tres años después en Barcelona bajo el título de La crisis del humanismo. Otro tanto hizo Salvador de Madariaga con varias obras. En Navarra y el País Vasco se cuenta con precedentes al menos desde que Sancho de Elso y el Doctor Ostolaza escribieran en el siglo XVI sendas doctrinas cristianas en castellano y vascuence. Años después, en el siglo XVII, Juan de Beriain componía en vasco y en castellano un Tratado de cómo se ha oyr missa (I6I2) y una Doctrina cristiana (I626). Un siglo más tarde el jesuita Manuel de Larramendi incluía en su $\mathrm{El}$ imposible vencido: Arte de la lengua bascongada (I729) varios poemas en vascuence con su correspondiente traducción castellana y Resurrección Ma de Azkue publicaba en I89i en edición bilingüe propia una Gramática eúskara. En el siglo XX Nicolas Ormaechea «Orixe» tradujo a prosa castellana alguno de sus poemas, como hizo también posteriormente Carmelo de Echegaray (1865-I925) con su poema Arrigoriaga. Algo más tarde, el poemario de Juan Larrea Versión celeste aparece publicado inicialmente en traducción italiana de Vittorio Bodini (1969) e incluye en su edición española, publicada en Barcelona un año después, poemas originales en español y en francés y traducciones al español de los textos franceses originales; las traducciones del original francés de Larrea al castellano son del propio autor, de Gerardo Diego, de Luis Felipe Vivanco y de Carlos Barral.
Si hablamos de autores contemporáneos que se hayan traducido a sí mismos (al menos, en alguna ocasión) la lista no es breve. En el ámbito lingüístico del catalán hay que mencionar, además de a Mendoza, a Carme Riera, Flàvia Company, Baltasar Porcel, Valentí Puig, Gabriel Gamés, Josep Riera, Pep Subirós, Joan Francesc Mira, Rafael Argullol, Pere Gimferrer, Joan Margarit, Lluís María Todó, Antoni Marí, Pau Faner, Roser Caminals, Josep Francesc Delgado o Terenci Moix, entre otros. Los escritores catalanes Agustí Bartra, Narcís Comadira, Feliu Formosa, Joan Perucho o Vicenç Llorca han autotraducido, sobre todo, su obra poética (citados en Tanqueiro 2002). Por su parte, en Galicia, donde Xosé Manuel Dasilva (2009) califica la práctica de la autotraducción como «incesante», no hay que olvidar a autotraductores de renombre como Ramón Cabanillas, Rosalía de Castro o Eduardo Rosal, durante el Rexurdimento; Álvaro Cunqueiro y Eduardo Blanco-Amor, en la posguerra; o Carlos Casares, Alfredo Conde, Manuel Rivas, Xurxo Borrazán o Suso del Toro; y, lo mismo en el País Vasco con Gabriel Aresti, Bernardo Atxaga (Joseba Iranzu Garmendia) o Felipe Juaristi.

Así, como indica Helena Tanqueiro (2002), el bilingüismo literario y la autotraducción no son dominio exclusivo de los mencionados países o sociedades plurilingües, sino que se produce en todas las partes del mundo y puede calificarse incluso de fenómeno natural en los países o sociedades mencionados.

\section{HITOS DE LA HISTORIA \\ DE LA AUTOTRADUCCIÓN}

Grutman (2009) considera que, cuando se estudia la autotraducción, se comete a menudo el error de conceder demasiada importancia a ciertos autores, única y exclusivamente porque trabajan 
con leguas centrales o dominantes, en detrimento de la gran mayoría de ellos: «Parece típico de cierta forma de crítica e historia literaria abordar el tema de la autotraducción de paso en un estudio monográfico. Como ha señalado Santoyo en varias ocasiones, los autores de tales estudios a menudo terminan confirmando el carácter excepcional del escritor que están comentando [...]. Al meramente yuxtaponer a Samuel Beckett y Vladimir Nabokov, a Julien Green y Nancy Huston, o a Dinesen y Eileen Chang, por ejemplo, se corre el riesgo de obtener poco más que una galería de retratos. Que sean interesantes estos autores, no hay quien lo ponga en tela de juicio, pero que algunos sean paradigmáticos, como se ha venido diciendo, es quizás otra cuestión». Aun estando totalmente de acuerdo con lo anteriormente expuesto, se ofrecen a continuación, con una mera función ilustrativa, algunos ejemplos de autotraductores remarcables.

Beckett es el autotraductor que más atención ha recibido y del que más estudios se han realizado además de, probablemente, la persona que despertó el interés por la autotraducción como sujeto de estudio ${ }^{2}$. La imposibilidad de encontrar un editor inglés para sus textos (considerados en la época como intraducibles) hizo que el autor tradujera al francés su obra Murphy, escrita en inglés y publicada en 1938 . A partir de 1946, Beckett escribe sólo en francés, algo que le resulta bastante difícil, y se autotraduce al inglés. El reconocimiento le llega en I953, año de la aparición de En attendant Godot y de Trilogie. La autotraducción al inglés de la primera, Waiting for Godot, aparece un año más tarde, en 1954, cuando se reconcilia con la lengua inglesa y escribe directamente en inglés From an abandoned work. El resultado dista de ser el esperado

2 La primera vez que la autotraducción constituye sujeto de estudio es en el artículo de Cohn (I96I). y lo vuelve a intentar dos años más tarde con All That Fall. A partir de ese momento, continua escribiendo en ambos idiomas e intercambiando las direcciones de la autotraducción. La obra de Beckett tiene un equivalente en el otro idioma para cada una de sus partes monolingües; así, cuando le fue concedido el Premio Nobel de Literatura en 1969, la Academia Sueca consideró el conjunto de sus textos en inglés y en francés como una sola obra y en el discurso de presentación del premio se subrayó su entrega a «un solo hombre, dos lenguas y una tercera nación [Irlanda]» (citado en Grutman 2009).

Otro ejemplo muy estudiado de autotraductor lo constituye el escritor, traductor, autotraductor y teórico de la traducción ruso Nabokov3. Hasta el éxito de Lolita en 1958 en EE.UU., su ya considerable obra rusa había pasado prácticamente desapercibida. A partir de ese momento, inicia la autotraducción de sus novelas rusas, sobre todo, al inglés, así como también la corrección de las versiones ya publicadas y las revisiones de las traducciones literales realizadas por colaboradores. Su especial relación con los idiomas le lleva a adoptar dos o incluso tres papeles distintos: el novelista americano, el novelista ruso, el novelista ruso autotraducido al inglés, haciendo dudar, de hecho, al lector inglés sobre si lo que lee es un original, una autotraducción, un traducción revisada por el autor o bien el trabajo de un traductor literario.

Green, por su parte, comenzó escribiendo en inglés y adoptó luego el francés como lengua de trabajo, lo que le permitió gozar de un gran reconocimiento. No son muchas sus autotraducciones, aunque sí realizó una muy importante, sobre todo, en lo que se refiere al bilingüismo: Le Langage et son double. The Language and its Shadows.

3 Más información acerca de este autor en la obra de Jane Grayson (I977). 
El caso del keniata wa Thiongo es también digno de mención, pues sirve además para reflejar el debate lingüístico existente en torno al uso de las lenguas propiamente africanas, como defiende el autor, frente al uso de lenguas no africanas, o lenguas de los colonizadores (inglés, francés o portugués) para escribir lo que se considera literatura africana. Wa Thiongo escribió en inglés hasta el año 1986, año en que publicó Decolonising the Mind: The Politics of Language in African Literature, obra que definió como su despedida del inglés en tanto que vehículo de escritura. A partir de ese año escribe todas sus obras en gikuyu, aunque luego se autotraduzca al inglés.

Milan Kundera nació en la antigua Checoslovaquia y, a pesar de ser uno de de los escritores checos más conocidos del mundo, es paradójicamente uno de los más desconocidos en su país de origen. Vive en Francia desde 1975, tras convertirse en disidente político, y es ciudadano francés dese 198I, año en que publicó El libro de la risa y el olvido, obra que le valió la revocación de su ciudadanía checa. En 1984 publica $L a$ insoportable levedad del ser, que no aparece en la República Checa hasta 2006, donde no fue bien acogido. La primera versión en checo apareció en 1985 en Toronto, obra de Jozef Skvorecky y Zdena Salivarova; posteriormente, Kundera reconstruyó el manuscrito original de la obra en francés, lo comparó con la versión de 1985 y, sobre todo, con la versión francesa, y se lanzó a la realización de la obra en checo. Si bien sus primeros libros fueron escritos en checo, desde I985 escribe directamente en francés y se niega a ser traducido por otras personas.

Por último, quisiera mencionar el caso del griego Vasilis Alexakis, instalado en Francia desde 1967, año en que se instaura en Grecia la dictadura de los Coroneles. Sus primeras obras están escritas en francés y en I98I, tras, o más bien, debido a lo que podría llamarse una crisis de identidad, escribe su primer libro en griego, que autotradujo dos años más tarde al francés, acción que dio pie a lo que ha venido siendo desde entonces la tónica de su actividad creadora: la autotraducción entre el griego y el francés, en ambas direcciones. El estudio de este autor, por consiguiente, es especialmente interesante no sólo por esa constante práctica autotraductora, sino también por el hecho de que los elementos autobiográficos, la problemática lingüística y su influencia sobre la percepción de la propia identidad configuran algunos de los rasgos más importantes en muchas de sus obras, hasta el punto de alcanzar en ocasiones casi el rango de personajes.

Existen otros muchos casos más, pero los límites del presente artículo impiden citarlos. Este breve repaso, lejos de buscar crear una galería de retratos, pretende ofrecer una imagen, al menos, aproximada del complejo panorama de la autotraducción, de sus múltiples manifestaciones y, sobre todo, de la inmerecida negligencia con la que ha sido tratado el fenómeno desde sus orígenes.

\section{¿QUÉ ES, EN REALIDAD, UNA AUTOTRADUCCIÓN?}

La concepción de la traducción ha cambiando mucho desde los siglos XVII y XVIII cuando en Francia, durante la llamada época de las Belles infidèles, la separación entre autor y traductor no obedecía a las mismas fronteras a las que obedece hoy. Así, en el siglo XVIII, el poeta francés Charles-Pierre Colardeau, argumentaba: «S'il y a quelque mérite à traduire, ce ne peut être que de perfectionner, s'il est possible, son original, de l'embellir, de se l'approprier, de lui donner un air national et de naturaliser, en quelque sorte, cette plante étrangère» (citado en Berman 1985). Más tarde, John Dryden (1978) establece los límites del traductor de acuerdo 
con tres formas distintas de traducir: la metafrase o traducción literal (mot à mot); la parafrase, o traducción libre, pero siempre sujeta al original; y la imitación o completa libertad para cambiar el original motivada por el deseo de alcanzar la misma perfección del original y que da lugar al término bermaniano de defectividad.

Frente a esto, la práctica de la autotraducción, fundamentada en concepciones traductológicas diametralmente opuestas a las clásicas, evidencia la fusión entre las competencias del autor y del traductor y permite, por sí misma, una serie de transformaciones transtextuales prohibidas, en principio, a la traducción. Además, su sola existencia plantea la dificultad intrínseca de su definición: ¿de qué hablamos cuando nos referimos a una autotraducción? ¿Se trata de una traducción, de un nuevo original, de una obra en evolución, de una segunda versión, de una versión definitiva que viene a suplantar la primera...?

\section{Autotraducción como punto intermedio entre creación y traducción}

$M^{a}$ Carmen Molina Romero (2003) defiende este punto de vista cuando dice que «La autotraducción puede jugar bastante con el grado de adaptación que el autor va a realizar del primer texto al segundo, y que va desde la traducción literal a la versión libre o incluso a la creación de un texto completamente distinto. Generalmente, las autotraducciones se encuentran en un punto intermedio entre estos dos polos (traducción-versión). Ello resultará, en gran medida, de la experiencia propia e intransferible del autor con cada una de ellas. La relación de un escritor bilingüe con su(s) lengua(s) es más compleja de lo que pudiera parecer y a menudo se encuentra presente en el propio proceso de escritura, incluso antes de que la actividad traductora intervenga».

\section{Autotraducción como creación y traducción}

Michael Oustinoff (200I) dice que si partimos del hecho de que la escritura y la traducción tienen una base común y, por tanto, los frutos del escritor y del traductor son equivalentes, puede deducirse que un autor que se traduzca a sí mismo producirá al mismo tiempo un texto y una traducción, esto es, una versión entera de la obra de la que deriva (lo que Henri Meschonnic llama «traducción texto» o Walter Benjamin «transposición poética»). Por su parte, la consideración de Gérard Genette (1982) de la traducción presupone la existencia de un hipotexto (el original) y un hipertexto (la versión traducida). En el caso de la traducción, la condición del hipertexto puede ser cuestionada y considerárselo como un «no texto». En el caso de la autotraducción, esto no es posible, y la versión traducida, en tanto que procede de la mano del autor, gozará ipso facto de carácter textual. Argumenta también que existen dos formas fundamentales de relaciones hipertextuales: la transposición (a la que pertenece la traducción) y la imitación (lo que le lleva a hablar de «mimotexto»). Según él, la autotraducción participaría, al mismo tiempo, de esas dos relaciones. Los defensores de que la traducción debe excluir todo acto creativo cuestionan sistemáticamente las argumentaciones anteriores y, basándose en la máxima anterior, se preguntan cómo es posible que un texto, en nuestro caso, una autotraducción, pueda ser al mismo tiempo una cosa y su contraria.

\section{Autotraducción como traducción}

Friedrich Scheleiermacher en su ensayo «Sobre los diferentes métodos de traducir» sostiene que «la cuestión de cómo [un autor] habría escrito sus obras en otra lengua no habría siquiera que formularla» ya que «nadie escribe una obra original sino en la lengua materna» (en Vega I994). De ahí que, para él toda autotraducción 
haya de ser considerada única y exclusivamente como traducción. Por su parte, James McFarlane entiende la autotraducción como un acto motivado por el interés de producir un texto nuevo más que por la recepción de dicho texto, de ahí que la autotraducción para él sea claramente una traducción: «même si nous trouvons un poète assez compétent pour entreprendre la composition en deux langues différentes, ses poèmes seront inadmissibles si l'un d'eux n'est que le résultat d'une traduction entreprise plus tard qui est littérale ou d'inspiration mot-à-mot» (citado en Fitch 1983).

Para Brian Fitch (1985) la actividad de la autotraducción es una actividad aventajada desde el punto de vista de la traducción. En esa misma línea, sostiene Tanqueiro (1999) que el autotraductor debe situarse más entre los traductores que entre los autores porque «aunque en su calidad de autores continuarían disponiendo de unas libertades que no se pueden permitir los demás traductores y se encuentran en una situación privilegiada por el acceso que tienen a la "verdadera intención" del autor, en el momento en que empiezan a traducir, el proceso de creación del universo ficcional ya se encuentra acabado en la obra original y los lectores ideales ya están definidos».

\section{Autotraducción como recreación (segundo original o versión)}

Cuando Georges Mounin (1995) dice: «Tous les arguments contra la traduction se résument en un seul : elle n'est pas l'original» lo que hace es oponer el original a su traducción y, por tanto, también a su autotraducción. Ahora bien, una autotraducción, a pesar de tener un precedente, que sería ese original existente en otra lengua, también es, en cuanto producto de la mano del autor, un original.

Fitch (1985) remarca: «the writer-translator is no doubt felt to have been in a better position to recapture the intentions of the author of the original than any ordinary translator. [...] In terms of its production, an auto-translation also differs from a normal one, if only because it is more of a double writing process than a two-stage reading-writing activity. As a result, the original's precedence is no longer a matter of 'status and standing' of authority, but becomes 'purely temporal in character'. [...] The distinction between original and (self-) translation therefore collapses, giving place to a more flexible terminology in which both texts are referred to as 'variants' or 'versions' of equal status». Lo mismo opina Blake Hanna (1972), quien defiende que la autotraducción no se encuentra subordinada a la versión original, y que original y traducción deben ser considerados como manifestaciones idénticas del pensamiento del autor. En esas condiciones, ¿es justo hablar de traducción? Ella dice que no, al menos, en sentido estricto del término; más apropiado es hablar de dos versiones de la misma obra, resultado de un mismo pensamiento, concebidas para dos públicos diferentes y destinadas a coexistir por el autor, y pone de relieve la importancia de la situación del autotraductor ante esta realidad doble.

\section{Autotraducción como continuación del original}

La autotraducción plantea el problema de la alteridad de la versión autotraducida, lo que conduce a su vez a plantearse la localización de la obra: ¿dónde hay que buscarla, en el original, en la autotraducción o en los dos a la vez? Dice Oustinoff (200I) que ésta se localiza normalmente tanto en el original como en la autotraducción; de ahí que pueda afirmarse que ambos se complementan y constituyen obras inacabadas por separado, por lo que la obra total no es sino el conjunto de las versiones existentes. En este caso, a diferencia de lo que ocurre con la

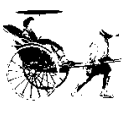

201 
traducción, la autotraducción se caracterizaría por la posibilidad de intercambio con el texto original y supondría la continuación de aquel. Ambos textos estarían en pie de igualdad, salvo en el plano cronológico. A esto se opondría seguramente Nabokov, quien únicamente consideraba la versión inglesa de sus obras como definitiva e intentaba siempre que sus traductores la tomasen como modelo.

\section{¿QUIÉN SE ESCONDE DETRÁS DE UN AUTOTRADUCTOR?}

En términos generales, existen dos claras tendencias a la hora de intentar establecer el estatus del autotraductor:

\section{Autotraductor como traductor}

Tanqueiro, en su artículo titulado «Un traductor privilegiado: el autotraductor» (I999), define al autotraductor como «traductor, porque, a pesar de su libertad de autor y de los privilegios que le supone su doble calidad de autor/traductor, [...] a la hora de traducir utiliza en gran medida estrategias propias de cada traductor/a». Así pues, el proceso creador de un nuevo texto en la lengua meta queda prácticamente anulado en la autotraducción. El texto traducido por su propio autor es nuevo en cuanto ocupa un sitio en la cultura de llegada, pero no así para el traductorautor, ya que el proceso de descodificación del texto origen no existe para el autotraductor, que inicia directamente su labor traductora con la codificación del texto en la lengua meta.

\section{Autotraductor como escritor}

A pesar de que es el anterior punto de vista el que predomina a la hora de considerar el estado del autotraductor, es cierto que, en ocasiones, la labor autotraductiva se aleja del mero hecho translativo y el autotraductor, como escritor y creador, se deja llevar por su creatividad e introduce elementos en la autotraducción inexistentes en la primera versión. Según Fitch (1983), mientras que el traductor es lector antes de convertirse en escritor, el autotraductor, por su parte, es desde el principio y será siempre escritor. Aún cuando el autotraductor quisiera o pudiera reproducir para el lector su propia recepción del texto original, su situación es distinta a la del traductor y las diferencias no se deben sólo a la distinta naturaleza de la experiencia que el autotraductor tiene del texto original, sino también de su relación con la realidad, como argumenta Anton Popovič (citado en Fitch ib.). Igualmente, Gregory Rabassa (2005) dice que el traductor es un lector que escribe lo que lee. Por lo tanto, un autotraductor es un lector que escribe lo que ya ha leído porque lo escribió en otra lengua; es decir, es dos veces, escritor. Y puesto que la lectura de una obra conlleva irremediablemente una interpretación de la misma, hay que plantearse hasta qué punto la primera versión es igual a la segunda versión pues, de acuerdo con este punto de vista, toda autotraducción supondría cambios respecto del primer texto.

A este respecto, Valentina Mercuri (2009) y Ovidio Carbonell (I997) hablan del traductor como un mediador cultural. Carbonell lo define como un mediador entre culturas «atrapado entre sistemas de representación y estructuras ideológicas manifestadas a través del lenguaje, de los que el texto es una mera superficie» y que «se debe, sobre todo, a la cultura de destino a la que traduce, con lo que deberá ajustar su propia interpretación del texto a las expectativas del contexto de recepción». Normalmente, la cultura de destino suele ser la cultura propia. En el caso del autotraductor, esa cultura puede ser la propia, en el caso de personas multiculturales, o puede ser una cultura ajena. 


\section{UNA CRÍTICA DE LA AUTOTRADUCCIÓN, ¿ES POSIBLE?}

Francesc Parcerisas (2002) dice que «El autotraductor no se halla sólo en posesión, como suele estarlo cualquier otro traductor, de propuestas de análisis y juicio para decidir entre los elementos semejantes y disímiles de dos culturas y dos lenguas, sino que, además, se halla en posesión de una llave que le brinda el acceso a lo más arcano de la traducción: el derecho a la libre creación». Y continúa: «El autor/traductor, en su función de autotraductor puede, pues, permitirse actuar con unas libertades que quedan amparadas por la libertad de su "real gana"». Las soluciones adoptadas por el autotraductor serán más o menos aceptables, más o menos acertadas a ojos del lector, pero en todos los casos serán indiscutibles porque, como dice Santoyo (2002b): «[...] ambos textos, original y traducción, llevan una única firma, y el texto traducido responde a la misma voluntad creadora de la que emanó el texto original». En este punto entra en juego la noción de «interferencia lingüística», en tanto que obstáculo inevitable para todo bilingüe (sea o no escritor).

Oustinoff (200I), a este respecto, establece una diferenciación entre lo que podría denominarse la crítica interna, que sería la realizada por los propios autotraductores sobre sus propias autotraducciones, y la crítica externa de la autotraducción, realizada por otras personas. En cualquier caso, hay que tener en cuenta que, tradicionalmente, la crítica de la traducción se realiza de acuerdo con lo que se ha dado en denominar "pérdidas y ganancias»; ahora bien, esos dos conceptos resultarían inservibles aplicados al estudio de textos autotraducidos. $\mathrm{Si}$ consideramos que el autotraductor, en tanto que autor y traductor a la vez, tiene todos los derechos, no se podrá hablar entonces de pérdidas y ganancias como tal, de defectividad de la lengua meta, sino de transformaciones presentes en el texto autotraducido con respecto al original.

¿Es posible, por lo tanto, hablar de errores de autotraducción? Quizás lo sea hablar de errores de escritura o de expresión aunque, incluso en ese caso, siempre habría que tener en cuenta la noción de «interferencia» y plantearse hasta qué punto las interferencias culturales han de ser consideradas errores sin importancia y perdonables o efectos de estilo de pleno derecho, en tanto que manifestaciones voluntarias de un determinado estilo de escritura. En cualquier caso, aun no tratándose de interferencias lingüísticas o culturales, incluso no tratándose de deslices, ¿puede reprochársele algo a un autotraductor y, por lo tanto, autor, en la elaboración de su propia obra, más allá de las reacciones que ésta despierte en el lector? ¿Podemos hablar técnicamente de una crítica de la autotraducción? Oustinoff (200I) señala que sólo el intentarlo sería «se condamner à corriger la copie de l'élève Nabokov ou de l'élève Beckett».

\section{¿POR QUÉ ESCRIBIR LO MISMO (O NO) DOS VECES?}

Así pues, si en principio, para el autotraductor, el problema de la interpretación errónea del texto base no existe y, por lo tanto, tampoco en teoría, el de la manipulación que conlleva toda traducción en el sentido en el que se pronunciaron Lawrence Venuti (1995), Susan Bassnett (1997 y 2006) o André Lefevere (1992 y 1997), entre otros, hay que plantearse una cuestión: ¿qué pretende el autotraductor con la realización de su obra en una lengua diferente a aque1la en la que ya la realizó una vez? Dice Whyte (2002): «The practice of self-translation is never innocent» $y$ no son pocos los autotraductores que han aclarado abiertamente qué les llevó a autotraducirse. Así, los principales motivos para la autotraducción serían, en primer lugar, 
razones económicas; en segundo lugar, razones de prestigio y la búsqueda de un público más extenso; y, en tercer lugar, de desconfianza hacia traducciones realizadas por terceros, pues para gran parte de autotraductores, el autotraducirse implica evitar una traducción posterior, e insatisfactoria. Dasilva (2009) añade el hecho de que la autotraducción facilite la profesionalización del escritor que trabaja con una lengua minoritaria (a través del periodismo, por ejemplo), «aprovechando que la línea divisoria entre el autor monolingüe que se autotraduce y el autor bilingüe es muy tenue».

En contrapartida, podríamos hablar de aquello que lleva a los escritores bilingües a no iniciarse en el ejercicio de la autotraducción y que se ha dado en llamar en inglés «the horror of selftranslation». En palabras de Raymond Federman (I996): «Even though finished, the book feels unfinished if it does not exist in the other language. Often I begin such an alternate version, but quickly abandon it, out of boredom, I suppose, fatigue or disgust, or perhaps because of what you call "the horror of self-translation", the fear of betraying myself and my own work». Sentimiento este compartido por otro autor bilingüe, Paul Auster ${ }^{4}$, quien afirma no sentirse preparado para autotraducirse, aun cuando reconoce que la lectura de sus obras en idiomas que él conoce le producen un sensación extraña: «on se sent toujours un peu étranger à soi-même dans une autre langue» o por el italiano Antonio Tabucchi, traductor de Fernando Pessoa al italiano y autor de la obra Requiem en portugués, quien a la pregunta de por qué nunca se autotradujo responde: «quien sabe si no es la razón principal, he tenido miedo, me ha faltado valor para recorrer al mismo tiempo mis dos orillas lingüísticas y afectivas por

\footnotetext{
4 Entrevista aparecida en la revista TGV Magazine 62,2004
}

hablar en términos psicoanalíticos. He sido capaz de ir hasta la otra orilla, pero no de volver atrás con la misma barca» (citado en Gumpert 1995).

Por último, en el caso de Galicia, según Dasilva (2009), la negativa a autotraducirse puede interpretarse como un gesto de reivindicación de la identidad cultural.

\section{TIPOLOGÍA DE LA AUTOTRADUCCIÓN}

Tras todo lo anteriormente expuesto, podemos clasificar los distintos tipos de autotraducción, en función de las diferentes variantes que intervienen en el proceso de creación.

I. Siguiendo a Oustinoff (200I) y atendiendo al proceso de realización de la autotraducción, podemos hablar de tres categorías principales:

- Autotraducción naturalizante («auto-traduction naturalisante o doxale»). Consiste en someter al texto única y exclusivamente a las normas de la lengua meta y eliminar toda interferencia procedente de la lengua origen o, lo que es lo mismo, naturalizar la traducción. El producto obtenido se adecua a lo que Mounin denominó la práctica de los cristales transparentes y queda justificada por la búsqueda de una equivalencia de efecto, de legitimidad en sí misma. Sería el caso de las autotraducciones de Joseph Conrad.

- Autotraducción descentrada. Es la que se aleja de las normas de traducción consideradas independientemente de su valor, de ahí que ese descentramiento pueda adoptar formas muy diferentes. Obedece a lo que Antoine Berman (I984) llamó la visión etnocéntrica de la traducción. Según Oustinoff (200I), algunas autotraducciones de Nabokov y de Beckett pertenecen a esta categoría, en tanto que presentan claras reminiscencias de la lengua materna en la lengua de la autotraducción. 
- Autotraducción (re)creadora. Aquella en la que el autor adopta todas las libertades posibles al autotraducirse, dando lugar a un estado más avanzado de transformación que la modalidad anterior. Oustinoff afirma que las autotraducciones realizadas desde un idioma subalterno (dominado o periférico) aspiran a ser primordialmente de este tipo: "productos en los que sobresale una actuación omnímoda del autor al trasladar su texto a otra lengua» y que se caracterizan por «una nítida desproporción entre las dos facetas del autotraductor como autor y como traductor a favor de la primera de éstas» (citado en Dasilva 2009). De este modo, y de nuevo en palabras de Dasilva, el resultado es «un texto traducido que, en lugar de suponer un reflejo del texto de partida, se transmuta más bien en una creación artística autónoma». De nuevo, algunas de las autotraducciones de Nabokov y Beckett son ejemplos de esta categoría.

2. Considerando el efecto conseguido por la autotraducción en el lector y a la identidad operativa de la autotraducción (la cual está mayormente relacionada con la intención del autor), habrá que diferenciar entre:

- Autotraducción esperada o previsible. Es la autotraducción destinada a mantener la identidad operativa del original y que nos lleva a afirmar que, por ejemplo, Waiting for Godot es la misma obra que En attendant Godot, con la única diferencia del idioma utilizado.

- Autotraducción libre o autotraducción revisora. Es la autotraducción que da lugar a lo que George Steiner denomina «efecto curioso» cuando habla de las traducciones de Beckett o la «viable eccentricity» de Kenneth Rexroth.

3. En función del producto obtenido en tér- minos cuantitativos, habrá que distinguir entre:

- Autotraducción explicitadora. Es aquella que completa en alguna manera la primera versión, mediante la aportación de elementos inexistentes en aquella, como ocurre con algunas autotraducciones de Nabokov o de Beckett. La comparación de ambas versiones ofrece aclaraciones en ambas direcciones.

- Autotraducción implicitadora. Es aquella que elimina datos proporcionados por la primera versión, por lo que se hará necesaria una lectura de la primera obra para llegar a una compresión completa de la autotraducción.

4. Atendiendo al tiempo trascurrido entre la elaboración del original y de la autotraducción, distingue Grutman entre:

- Autotraducción simultánea («simultaneous auto-translation») que es la que se lleva a cabo al mismo tiempo que la primera versión. Para Riera (2002) este método de trabajo es el ideal, pues le «ofrecía un punto de vista diferente para poder observar cómo funcionaba en la otra lengua y para poder así corregir los aspectos que me parecían pertinentes porque me convertía en una lectora crítica de mi propio texto, mucho más distanciada que cuando leía en mi propia lengua después de escribir, para corregir. El filtro que suponía pasar por otro idioma me permitía, seguramente, objetivar mucho más, me convertía en una receptora y no en una emisora del texto en cuestión».

- Autotraducción retardada («delayed autotranslation») que es la publicada tras la finalización o incluso la publicación del manuscrito original.

Añadiré a este apartado una nueva categoría:

- autotraducción simultánea bidireccional. Sería la llevada a cabo por Lluís María Todó (2002) para la elaboración de su obra $L a$ adoración perpetua y que él mismo describe

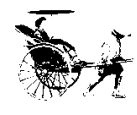

205 


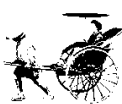

206 del modo siguiente: «lo fui redactando en catalán y en castellano alternativamente, siguiendo impulsos cuya naturaleza exacta ignoro, y después traduje al castellano los capítulos al catalán, y viceversa».

5. Teniendo en cuenta el papel de autotraductor en tanto que único traductor o no, hay que hablar de:

- Autotraducción autorial (de acuerdo con la denominación de Gerard Genette) vs. traducción apócrifa («allographe»).

- Autotraducción parcialmente autorial. Es aquella en la que el autor del original no realiza el conjunto de la autotraducción, sino que trabaja en colaboración con otra(s) persona(s). Sería el caso de la versión francesa de Ulises de James Joyce y también el de Jorge Luis Borges (en el caso de algunos cuentos) o de Beckett (quien tradujo junto con Richard Seaver dos novelas cortas de The Expelled and Other Novellas).

- autotraducción parcialmente autorial revisora. Bastante común, sobre todo, al inicio de la práctica autotraductora de muchos autores. Practicada en ocasiones por Nabokov, quien pedía a sus colaboradores una traducción intermedia, lo más literal y explícita posible, sobre la que llevaba a cabo una revisión totalmente libre y creativa. Es el caso también de William Beckford y su obra Vanthek, el de Salomé de Oscar Wilde o el de la traducción de Obabakoak de Atxaga.

6. Basándose en la relación existente entre las lenguas de trabajo y la direccionalidad, Molina Romero (2003) distingue entre:

- Autotraducción trans-lingüistica. Aquella en la que tanto la lengua de partida como la lengua de llegada forman parte de una misma realidad nacional. Es el caso de las autotraducciones realizadas por los escritores gallegos, vascos o catalanes hacia o del castellano.
- Autotraducción trans-nacional. Es, por el contrario, aquella en la que la lengua de partida y la lengua de llegada pertenecen a dos realidades nacionales distintas. Caso por ejemplo de las autotraducciones al inglés del escritor ruso Nabokov o de las autotraducciones al francés del griego Alexakis.

Grutman (2009), considerando el mismo criterio, pero basándose en la existencia de un sistema jerárquico en la denominada «galaxia de las lenguas» distingue entre:

- autotraducción de un idioma simbólicamente dominante o «central» a un idioma «periférico» $(y$ viceversa). Es el caso de las autotraducciones del bengalí al inglés de Tagore.

- autotraducción de un idioma dominante a otro idioma dominante, como hacía Beckett entre el inglés y el francés.

- Autotraducción de un idioma dominado a otro idioma dominado. El menos frecuente, por motivos obvios.

7. Si tenemos en cuenta, de nuevo, la relación entre las lenguas de trabajo, pero considerando el resultado obtenido directamente por el autor, podríamos hablar de:

- autotraducción «rentable». La más común, aquella que se lleva a cabo desde una lengua, llamémosla, minoritaria a otra mucho más extendida geográficamente o de mayor prestigio. Tiene por objetivos alcanzar un público más extenso y mayores beneficios económicos y de prestigio.

- autotraducción «reparadora». La que la se realiza de una lengua mayoritaria o con mayor prestigio a una minoritaria, generalmente motivada por factores psicológicos o afectivos. Dinesen constituye un claro ejemplo: tras haberse asegurado un lugar en el panorama literario internacional con sus obras en inglés, decide dirigirse en su lengua materna a los lectores daneses, según 
Lisa Kure-Jensen (1993) como muestra del reconocimiento y del respeto por la tradición literaria danesa y su público.

8. Por último, podemos hablar de la autotraducción como herramienta de diferenciación de género literario (Parcerisas 2002). Muchos autores se sirven de la práctica de la traducción en otros idiomas en este sentido. Así, Mendoza, por ejemplo, es novelista en castellano y dramaturgo en catalán; Riera es ensayista en castellano y narradora en catalán; y Margarit autotraduce poemas antiguos y escribe indistintamente en catalán y castellano sus poemas más recientes.

\section{TODO ES TAN IMPORTANTE COMO SE QUIERA QUE SEA. CONCLUSIÓN}

Los cada vez más numerosos contactos entre lenguas, gracias a la mayor movilidad de población, en todos los niveles, en todo el mundo, y el claro reforzamiento del sistema jerárquico entre las lenguas afectan al universo literario y están directamente relacionados con la práctica de la autotraducción. Afortunadamente, cada vez son más los estudios dedicados a este fenómeno, que parece poco a poco cobrar la importancia que merece.

¿Por qué es importante y qué tiene que ofrecer el análisis de una autotraducción? En tanto que objeto de estudio, la autotraducción plantea serias dificultades a la hora de su catalogación y establecimiento de pautas, al tiempo que evidencia uno de los aspectos más esenciales de la escritura: la relación que mantiene el escritor multilingüe con sus lenguas de trabajo. La importancia de esa relación en la obra y la influencia que cada una de las lenguas ejerce, ya no sólo sobre su escritura, sino también sobre el autor, sobre su percepción de la realidad y sobre su manera de expresar esa percepción justifican el esfuerzo. Asimismo, ese «derecho a todo» del que goza el autotraductor - que puede ser discutido, pero no negado- permite al estudioso de la autotraducción descubrir equivalencias lingüísticas entre las dos lenguas utilizadas, además de la dimensión cultural, psicológica e incluso emotiva conferida por el autor a sus palabras. El trasvase lingüístico autotraductológico afecta a numerosos parámetros interrelacionados de diverso carácter, como pueden ser la vinculación a una tradición, la relación con la oralidad, la adhesión o el rechazo a una determinada política lingüística, la búsqueda y la reconstrucción de una identidad, las relaciones con otras literaturas de un determinado país, las relaciones con determinadas personas y sentimientos motivados por una determinada lengua, la aceptación de otra lengua o la lucha por hacer ganar nuevos territorios a la propia... Todos estos aspectos constituyen elementos primordiales desde un punto de vista tanto sociolingüístico como traductológico a la hora de sacar a la luz el comportamiento lingüístico de un escritor y la relación que éste mantiene con cada lengua, además de servir como elemento revelador de la evolución tanto del estilo del autor como de su producción, ya sea de toda su obra o de una obra particular.

RECIBIDO EN OCTUBRE DE $20 I O$ ACEPTADO EN FEBRERO DE 2 OII VERSIÓN FINAL DE MARZO DE $20 I I$

\section{REFERENCIAS BIBLIOGRÁFICAS}

Bassnett, Susan; Bush, Peter (2006). The Translator as Writer. Londres, Continuum

-; Lefevere, André (1997). Constructing Cultures: Essays on Literary Translation. Londres, Multilingual Matters

Berman, Antoine (1984). L'Epreuve de l'Étranger. Culture et traduction dans l'Allemagne romantique. París, Gallimard

- (1999). La traduction et la lettre ou l'auberge du lointain. París, Seuil

Carbonell Cortés, Ovidio (1997). «Del "conocimiento del mundo" al discurso ideológico: El papel del

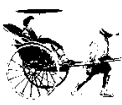

207 


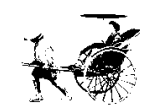

208 traductor como mediador entre culturas», en Esther Morilllas y Salvador Peña (eds.): El papel del traductor, Salamanca, Ediciones Colegio de España, 59-74

Cohn, Ruby (I96I). «Samuel Beckett Self-Translator». PMLA 76, 6r 3-2I

Dadazhanova, Munavvarkhon (I984). «Both are primary: An "Author's Translation" Is a Creative Recreation", Soviet Studies in Literature 20: 4, Open Society Archives, Armonk, Nueva York

Dasilva, Xosé Manuel (2009). "Autotraducirse en Galicia: ¿bilinguismo o diglosia?», Quaderns: revista de traducció I6, I43-I56

Dryden, John (1978). Preface to Ovid's Epistles. Londres, Methuen

Federman, Raymond (1996). $A$ voice within a voice: Federman Transalting/Translating Federman, [en línea]. <http://www.federman.com/rfsrcr2.htm> [consulta 3 de marzo de 20Io]

Fitch, Brian T. (1983): «L'intra-intertextualité interlinguistique de Beckett: la problématique de la traduction de soi», Texte 2, 85-100

- (1985). «The Status of Self-translation», Texte 4, III-25

Friedman, Alan Warren, et al. (eds.) (1987). Beckett Translating / Translating Beckett, University Park, Pennsylvia State University Press

Forster, Leonard (1970). The Poet's Tongue: Multilingualism in Literature. London, Cambridge University Press

Genette, Gerard (1982). Palimpsestes. La littérature au second degré. París, Seuil

Grayson, Jane (1977). Nabokov Translated. A Comparison of Nabokov's Russian and English Prose. Oxford, Oxford University Press

Green, Julien (1987). Le Langage et son double. The Language and its Shadows. París, Éditions du Seuil

Grutman, Rainier (I998). «Auto-translation», «Multilingualism and translation», en Mona Baker (dir.): Encyclopedia of Translation Studies, Londres, Routledge, I7-20; I57-I60

- (2009). «La autotraducción en la galaxia de las lenguas». Quaderns: revista de traducció I6, I23-I34

Gumpert, Carlos (1995). Conversaciones con Antonio Tabucchi. Anagrama, Barcelona.

Hanna, Blake T. (I972). «Samuel Beckett traducteur de lui-même», Meta. Journal des Traducteus-Translators' Journal 4: I7, Montreal, 220-24

Lefevere, André (1992). Translation, Rewriting, and the
Manipulation of Literary Fame. Londres y Nueva York, Routledge

Mercuri, Valentina (2009). «Autotraducción, libertad de autor y mediación cultural: El caso del italiano Carlo Coccioli». Quaderns. Revista de traducció $\mathrm{I} 6, \mathrm{I}_{35}-\mathrm{I} 42$

Molina Romero, María del Carmen (2003). «De L'Aveuglon a Marruecos: una lectura a contrapelo de Agustín Gómez Arcos». Espéculo. Revista de estudios literarios, [en línea]. <http://www.ucm.es/ info/especulo/numero23/cmolina.html> [consulta 3 de marzo de 20Io]

Mounin, Georges (1995). Les belles infidèles. París, Cahiers du Sud

Oustinoff, Michael (200I). Bilinguisme d'écriture et auto-traduction. Julien Green, Samuel Beckett, Vladimir Nabokov, París, L'Harmattan

Parcerisas, Francesc (2002). «Sobre la autotraducción», Quimera 210, I3-I4

Rabassa, Gregory (2005). If this be treason: translation and its dyscontents: a memoir. New Directions Book, Nueva York

Riera, Carme (2002). "La autotraducción como ejercicio de recreación». Quimera 210, IO-I4. [Trad. de Dolors Poch]

Santoyo, Julio César. (2002a). «Traducciones de autor: Una mirada retrospectiva», Quimera 210, 27-32.

- (2002b). «El reto del trasvase cultural: cuando el autor es también traductor», en Isabel Cómitre Narváez y Mercedes Martín Cinto (eds.): Traducción y Cultura. El Reto de la Trasferencia Cultural, Málaga, Libros ENCASA. Ediciones y Publicaciones

Scheleiermacher, Friedrich (I994) [I8I3]. «Sobre los diferentes métodos de traducir» trad. V. García Yebra, en M. A. Vega (ed.) Textos clásicos de teoría de la Traducción, Madrid, Cátedra, 224-235

Tanqueiro, Helena (I999). «El autotraductor - un traductor privilegiado", Quaderns. Revista de Traducció $3,19-27$

- (2002). Autotradução: Autoridad, privilégio e modelo. Tesis doctoral, Universidad Autónoma de Barcelona

Todó, Lluís María (2002). «Lugares del traductor», Quimera 210, I7-I9

Venuti, Lawrence (1995). The Translator's Invisibility. A History of Translation.Londres y Nueva York, Routlegde

Whyte, Christopher (2002). «Against Self-Translation», Translation and Literature II, Edimburgo, Edimburgh University Press 